\title{
CONTEXTOS NÃO ESCOLARES E PESQUISA EM EDUCAÇÃO AMBIENTAL: QUESTÕES E DESAFIOS OBSERVADOS NOS ENCONTROS DE PESQUISA EM EDUCAÇÃO AMBIENTAL (EPEAS)
}

\author{
Priscila Amaro Lopes ${ }^{1}$ \\ Fernando Protti Bueno ${ }^{2}$ \\ Maryane Vieira Saisse ${ }^{3}$
}

\begin{abstract}
Resumo
O Grupo de Discussão de Pesquisa (GDP) Educação Ambiental em Contextos não escolares foi criado como recorte temático dos Encontros de Pesquisa em Educação Ambiental (EPEA), em 2011. Este artigo teve por objetivo refletir sobre os desafios e avanços obtidos nesse grupo de discussão, que tem acolhido investigações relevantes em diferentes contextos e que, aos poucos, vem consolidando sua identidade e especificidade. A análise dos trabalhos apresentados na edição de 2017 mostrou maior concentração das pesquisas em contextos de comunidades e Unidades de Conservação. Também foram observadas sobreposições em relação a outros GDPs. Questões relevantes como os limites para o enquadramento do que se denomina não escolar nas pesquisas ainda estão em processo de apuração, porém a densidade e o aumento do número de trabalhos inscritos e aprovados no último EPEA refletem o amadurecimento nessa área de pesquisa.
\end{abstract}

Palavras-chave: Educação ambiental. Contexto não escolar. Grupo de discussão de pesquisa (GDP).

\section{NON-SCHOOL CONTEXT AND RESEARCH IN ENVIRONMENTAL EDUCATION: ISSUES AND CHALLENGES OBSERVED IN MEETING OF RESEARCH IN ENVIRONMENTAL EDUCATION (EPEAS)}

\begin{abstract}
The Group Discussion Research (GDP) Environmental Education in non-school contextswas created as a subtheme of the Environmental Education Research Meetings (EPEA), in 2011. This article is aimed in the reflection of the challenges and advances achieved in this discussion group that has receivedrelevant research in different contexts and, consolidating its identity and specificity. The analysis of the works presented in the 2017 edition showed a greater concentration of the researches in contexts of communities and Conservation Units, it was also observed the sobreposition with other GDPs works. Relevant questions such as the limits for the framing of what is called non-school in the surveys are still in the process of being assessed, but the density and increase in the number of papers registered and approved in the last EPEA reflects the maturation in this area of research.

Keywords: Environmental Education. Non-school context. Group Discussion Research (GDP).

\footnotetext{
1 Mestranda em Educação (PPGE/UFRJ). Educadora ambiental em projeto com comunidades do Rio de Janeiro (NEA-BC), na Associação Raízes. prisalopes@ @mail.com

2 Doutorando em Educação (UNESP, Rio Claro) e Professor do Curso de Turismo (UNESP, Rosana). fernando.bueno@unesp.br

Doutora em Psicossociologia de Comunidades e Ecologia Social (UFRJ). Pesquisadora do Laboratório de Investigação em Educação, Ambiente e Sociedade - LIEAS. Faculdade de Educação UFRJ. Educadora do Jardim Botânico do Rio de Janeiro, Rio de Janeiro, Brasil. mvsaisse@ gmail.com
} 


\section{CONTEXTOS NO ESCOLARES Y INVESTIGACIÓN EN EDUCACIÓN AMBIENTAL: CUESTIONES Y DESAFIOS OBSERVADOS EN ENCUENTRO DE INVESTIGACIÓN EN EDUCACIÓN AMBIENTAL (EPEAS)}

\section{Resumen}

El Grupo de Discusión de Pesquisa (GDP)Educación Ambiental en contextos no escolaresfue creado como recorte temático de los Encuentros de Investigación en Educación Ambiental (EPEA), en 2011. Este artículo tuvo por objetivo reflexionar sobre los desafíos y avances obtenidos en ese grupo de discusión que ha acogido investigaciones relevantes en diferentes contextos y que, poco a poco, viene consolidando su identidad y especificidad.El análisis de los trabajos presentados en la edición de 2017 mostró mayor concentración de las investigaciones en contextos de comunidades y Unidades de Conservación. También se observó superposiciones con respecto a otros GDP. Las cuestiones relevantes como los límites para el encuadramiento de lo que se denomina no escolar en las encuestas todavía están en proceso de escrutado, pero la densidad y el aumento del número de trabajos inscritos y aprobados en el último EPEA reflejan la madurez en esa área de investigación.

Palabras-clave: Educación ambiental. Contexto no escolar. Grupo de Discusión de Pesquisas (GDP).

\section{Introdução}

A educação ambiental, realizada fora das escolas e instituições formais, assume facetas múltiplas e bastante significativas no desenvolvimento desse campo. Nesse sentido, é importante que pesquisas se debrucem sobre esse contexto, e, nos últimos anos, elas têm se avolumado. O Grupo de Discussão e Pesquisa (GDP) de Educação Ambiental em Contextos Não Escolares dos Encontros de Pesquisa em Educação Ambiental (EPEAs) é um relevante espaço de trocas e debates entre os pesquisadores dessa área, desde 2011.

Este trabalho tem por objetivo refletir sobre as pesquisas apresentadas na IX edição do EPEA e sobre as questões levantadas nos debates do grupo, que dizem respeito à delimitação do contexto não escolar, sua relação com os outros GDPs do EPEA e os desafios apontados para as pesquisas desenvolvidas nesse contexto e para a continuidade do GDP.

Os trabalhos apresentados e as discussões resultantes nas quatro edições do GDP possibilitaram traçar um perfil das pesquisas desenvolvidas nesse campo e aprofundar o debate em torno de suas principais questões. Na intenção de realizar uma breve retrospectiva acerca do contexto não escolar, debatido nos GDPs nos anos de 2011, 2013 e 2015, e a partir de suas respectivas produções (HIGUCHI; ZATTONI; BUENO, 2012; HIGUCHI; MAROTI, 2014; SAISSE et al. 2016), apresentamos as principais concepções encontradas, buscando avançar no diálogo a partir dos trabalhos apresentados em 2017.

Ainda que se opte por não engessar o contexto aqui tratado, o não escolar, em uma única definição, percebemos ser importante dar algum continente ao seu entendimento, não só para dar coerência ao agrupamento dos trabalhos, como para não perder de vista as características das práticas educativas nele realizadas, suas potencialidades e desafios.

Os participantes do GDP de EA em contextos não escolares têm realizado, em cada uma de suas edições, um grande esforço para tratar as particularidades e diversas possibilidades de estudos e pesquisas que tratam desse contexto e, assim, compor um continente que dê certa unidade às considerações e discussões do coletivo.

Quando o referido GDP foi criado, no EPEA de 2011, foram inscritos doze trabalhos de pesquisa, nos quais a natureza era apresentada como o território mais recorrente onde as ações educativas eram desenvolvidas. Após uma diminuição no número de trabalhos presentes 
nesse GDP, no ano de 2013, quando apenas seis pesquisas foram apresentadas, em 2015 esse número cresceu, totalizando vinte trabalhos, o que representou $17 \%$ do total de trabalhos inscritos no EPEA. No entanto, desses, apenas sete foram aprovados, caracterizando o GDP naquele ano como o de menor número de trabalhos aceitos e apresentados. Nenhum/a autor/a dos trabalhos aprovados esteve presente nas discussões do Grupo, dificultando um maior aprofundamento nas reflexões sobre as pesquisas nesse campo.

De forma geral, desde sua criação tem-se observado diversos trabalhos inscritos nesse GDP que poderiam estar em outros grupos de discussão do Encontro, como de movimentos sociais e políticas públicas, por exemplo. Igualmente, registra-se, uns anos mais, outros menos, que vários trabalhos são inscritos e aprovados nesse GDP, mas seus autores, presentes ao evento, priorizam as discussões de outros GDPs por considerarem-nas mais afeitas ao seu objeto de investigação, como já mostrado anteriormente para o ano de 2015.

Entendemos ser produtivo para esse debate indagar quem são os sujeitos, espaços e objetivos desses trabalhos e, ainda, como se relacionam com as discussões dos outros Grupos e as temáticas do evento. Não há como negar, entretanto, que são partes constituintes desse GDP as reflexões sobre sua identidade e os anseios por definir especificidades de suas pesquisas, por isso, buscamos avançar também nessas questões, enfrentando o desafio de dar prosseguimento ao que vinha sendo discutido desde os últimos Encontros.

\section{Contextos da Educação Ambiental Não Escolar}

A citação de Quintas (2004, p. 116): "Definir galinha como a ave que não é pato não diz nada sobre ela. Pode-se saber tudo sobre patos, mas por esta definição continua-se não sabendo nada sobre galinhas" mostra, de forma simples, dos riscos de simplificação e as armadilhas contidas no que designamos como contextos não escolares da educação, afinal, não se trata apenas de definir a partir da negação do que não é escolar.

No intuito de avançar nas discussões sobre a especificidade e os desafios enfrentados pelas pesquisas na área de educação ambiental em contexto não escolar, tratamos brevemente do contexto em que foi criado e as principais questões que acompanharam o desenrolar do GDP que trata dessa área no EPEA.

Uma tentativa de definição do contexto não escolar, seja para abrigar as práticas de educação ambiental, seja para caracterizar a pesquisa em educação ambiental, foi realizada por Higuchi, Zattoni e Bueno (2012, p. 120), os quais consideraram contexto enquanto:

[...] um espaço de acontecimento social que não se limita por barreiras físicas, mas por territorialidades fluidas e intencionalidades próprias que transcendem aspectos de lugar. Existe, no entanto, uma dimensão temporal estabelecida como uma marcação de acontecimentos.

Estamos habituados a verificar os processos educativos sendo classificados a partir de diferentes espaços e formas, denominados por educação formal, não formal ou informal. Entretanto, caracterizar esses espaços não é uma simples tarefa, sendo que, muitas vezes, tais termos são utilizados de maneira polêmica e suas definições não são consensuais.

Trata-se de uma característica comum, ainda que resguardadas suas distinções, associar a educação ocorrida fora da escola aos termos não formal e informal. Especificamente, o termo não formal, muitas vezes, se vincula a ações educativas de natureza política e intencionalmente voltadas à transformação social, sendo comumente associado aos termos pedagogia social, educação social e aprendizagem por livre-escolha, por exemplo (MARANDINO, 2017). Porém, o próprio Ministério da Educação define como educação não formal aquelas iniciativas organizadas de aprendizagem que acontecem fora dos sistemas de ensino, não relacionando diretamente ao seu objetivo (BRASIL, 2005). 
É fato, conforme nos alerta Marandino (2017), que se ampliaram os espaços não formais de educação. E isto se deveu tanto ao contexto social e político que a educação tem ocupado na sociedade, bem como aos incentivos governamentais e apoio da iniciativa privada, principalmente atrelados à área de educação em ciências, com o aparecimento de variados espaços destinados à prática educativa.

Palhares (2008) também relata o crescimento e a multiplicação de processos, contextos e formas de socialização e de educação não escolar, tanto no aspecto não formal quanto informal. E isso, segundo a autora, em parte pode ser explicado como reação ao que é propagado como a crise da escola, seus métodos e limites, e propõe a descentralização dos conhecimentos específicos do domínio escolar.

Para além dessas classificações, mais adstritas ao espaço de realização do ato educativo, o aspecto não escolar poderia ser considerado como um contexto não vinculado ao currículo escolar ou aos processos de escolarização, ou seja, não restrito aos "espaços e tempos da instituição escolar" (PALHARES, 2008, p. 109). Isso nos permitiria estender o campo de visão e a reflexão na tentativa de verificar o papel dos demais espaços e das demais instâncias relacionadas à difusão de conhecimentos e saberes (HIGUCHI; ZATTONI; BUENO, 2012; PALHARES, 2008).

Retomando o debate sobre o contexto não escolar na educação ambiental, ainda naquela oportunidade, Higuchi, Zattoni e Bueno (2012, p. 121), afirmaram que este "se constitui num espaço de diálogos abertos às proposições inovadoras de integração, articulação e acolhimento de audiências e experiências socioambientais amplas". E, para tanto, caracterizaram a escola enquanto "lugar formal, [que] pode conter tanto a educação "escolarformal' quanto a 'não escolar', não formal e informal".

A partir do exposto, conforme asseveraram Saisse et al. (2016, p.136) naquele momento, o contexto não escolar da educação ambiental estava passível de entendimento a partir da "inter-relação entre o formal e o não formal da ação educativa e de certa preponderância da natureza como território para o desenvolvimento dessa relação". O que de fato foi suscitado por Higuchi e Maroti $(2014$, p. 97) ao considerarem que "a EA não se restringe a um lugar específico, mas que está em qualquer um deles e interfaceia muitos domínios". E, também, ao asseverarem, nas ideias de Guimarães (apud HIGUCHI; MAROTI, 2014, p. 97, grifo dos autores), que "o espaço da escola unifica um fazer, enquanto que o além dos muros se dispersa em vários outros fazeres, não menos importantes, da sociedade".

Posteriormente a esses postulados, Saisse et al. (2016, p.139-140) retomaram a discussão sobre os contextos escolares e não escolares da educação ambiental e as abordagens formais e não formais da aprendizagem, salientando que, de acordo ao observado nos trabalhos do GDP em contextos não escolares do EPEA, "a EA, em espaços outros que não a escola, pode ser nominada como EA não escolar". Portanto, parece, conforme afirmaram Higuchi e Maroti (2014), que a apropriação dos espaços fora da escola, bem como fora do sistema de ensino formal e dos processos de educação escolarizados, ou também denominados de além muros, continuam sendo um impasse e desafio à educação ambiental, seja na realização das práticas pedagógicas, seja na conformação de um campo de pesquisa.

Nesse sentido, temos percebido certa dificuldade de classificação/definição desse contexto, pois parece ainda não haver consenso sobre o que é o contexto não escolar da educação ambiental. A exemplo do que Marandino (2017) discutiu sobre o termo não formal, quando aplicado à educação, pensamos, também, que o movimento de discussão e sucessivas tentativas de compreensão e de definição do contexto não escolar de educação ambiental, por exemplo, possa contribuir para o enquadramento do campo de pesquisa, bem como para legitimar os próprios processos educativos relativos a esse contexto. 
Assim, ainda que as práticas pedagógicas ou as pesquisas realizadas não estejam totalmente enquadradas nesse contexto, isso não justifica a nossa perda de insistência na busca por melhor compreensão dos contextos não escolares da educação ambiental.

Temos entendido os contextos não escolares da educação ambiental como os que tratam a EA em contexto e espaço fora do ambiente escolar, entretanto, ainda se faz presente o questionamento se a educação ambiental em contexto não escolar poderia manter, em alguma medida, certa relação com a escola.

Por exemplo, o que dizer de uma investigação que tenha como objeto uma atividade educativa organizada por uma entidade fora da escola (ONG, empresas), mas cujo público esteja vinculado às escolas? Ou que seja realizada em uma estação de tratamento de esgoto, mas voltada para os estudantes? Ou uma ação formativa, como um curso de aperfeiçoamento, com características escolares, mas que ocorra, por exemplo, em museus? São questões que ainda suscitam debates entre os próprios pesquisadores.

De modo a contribuir nesse debate, uma proposta possível seria analisar essas situações, considerando como contexto não escolar, para as práticas pedagógicas e para o campo de pesquisas em educação ambiental, o espaço e o contexto fora do ambiente, das práticas e dos processos escolarizados, ou seja, fora dos muros e sem nenhuma relação com a instituição escolar.

Para isso, se fariam presentes e importantes as outras instituições e entidades que abarcam os demais equipamentos e espaços que detêm práticas e processos educativos disponíveis ao grande público. Entretanto, admitimos como possível que, em algum momento, a prática ou o processo de ensino e aprendizagem desenvolvidos com esse público relembrem, reproduzam ou se até se assemelhem ao modo formal de ensino.

Assim, o contexto não escolar assumiria a ideia de contexto anteriormente trabalhado por Higuchi, Zattoni e Bueno (2012), bem como se utilizaria do espaço não formal de educação, ou também denominado por espaços educadores - fora da escola/além dos muros (MATERAZI, 2005), e se restringiria aos públicos não escolares (sem vínculo com a escola). Estudantes podem fazer parte desse contexto, desde que não estejam no tempo da escola e que essa atividade educativa não seja fomentada, proposta e/ou realizada a partir do contexto escolar. Essa proposta, entretanto, ainda teria que ser debatida e aprofundada a partir de mais pesquisas do campo da educação, para que não sejamos levados a falar de galinhas como se fossem patos, como nos adverte Quintas (2004).

Assim, a fim de avançarmos nas discussões sobre a especificidade e os desafios enfrentados pelas pesquisas na área de educação ambiental em contexto não escolar, apresentamos algumas características das pesquisas apresentadas para o GDP EA e Contexto Não Escolar no ano de 2017, relacionando com o debate sobre o contexto desenvolvido até aqui e observando as sobreposições e relações entre os GDPs.

\section{As pesquisas em EA em contextos não escolares: uma análise dos trabalhos apresentados no IX EPEA}

Em 2017, na IX edição do EPEA, 165 trabalhos foram inscritos e 128 foram aprovados. O GDP Pesquisa em EA e Contexto Não Escolar (em sua quarta edição) recebeu catorze trabalhos ( $8,5 \%$ do total), dos quais doze foram aprovados, sendo o quarto GDP que mais recebeu trabalhos e um dos quatro com menor número de trabalhos reprovados. Dos catorze trabalhos inscritos, doze foram aprovados, e apenas um não foi apresentado no evento e, portanto, não será considerado neste estudo.

A análise dos trabalhos buscou verificar as principais características das pesquisas que se enquadraram no contexto não escolar nessa última edição do EPEA, a fim de entender melhor cada uma delas e o motivo de estarem nesse GDP. Também procuramos, a partir do 
debate realizado no item anterior, analisar como as pesquisas nesse GDP podem se relacionar com outros grupos de pesquisa.

Foram destacados, conforme pode ser visto no Quadro 1, o espaço/contexto, os sujeitos pesquisados, e o objetivo das pesquisas apresentadas na última edição. Não consideramos relevante para essa discussão, nesse momento, os métodos empregados ou os autores utilizados.

\begin{tabular}{|c|c|c|c|}
\hline $\begin{array}{l}\mathbf{N}^{\circ} \text { do } \\
\text { trabalho }\end{array}$ & Contexto & $\begin{array}{l}\text { Sujeitos/objetos da } \\
\text { pesquisa }\end{array}$ & Objetivo da investigação \\
\hline 1 & Ecovilas & $\begin{array}{l}\text { Literatura existente } \\
\text { sobre ações em } \\
\text { ecovilas }\end{array}$ & $\begin{array}{l}\text { Natureza e potencial } \\
\text { educativo das ações das } \\
\text { ecovilas em sua busca por } \\
\text { sustentabilidade }\end{array}$ \\
\hline 2 & Mídia impressa & Revistas & $\begin{array}{l}\text { Potencialidade didática de } \\
\text { revistas no tema da crise } \\
\text { hídrica }\end{array}$ \\
\hline 3 & Unidades de Conservação & $\begin{array}{l}\text { Moradores do } \\
\text { entorno da Unidades } \\
\text { de Conservação }\end{array}$ & $\begin{array}{l}\text { Percepção ambiental dos } \\
\text { moradores do entorno da } \\
\text { Unidades de Conservação }\end{array}$ \\
\hline 4 & Unidades de Conservação & $\begin{array}{ll}\text { Visitantes } & \text { da } \\
\text { Unidades } & \text { de } \\
\text { Conservação } & \end{array}$ & $\begin{array}{l}\text { Concepções e práticas dos } \\
\text { visitantes da Unidades de } \\
\text { Conservação }\end{array}$ \\
\hline 5 & Unidades de Conservação & $\begin{array}{l}\text { Estudantes da } \\
\text { educação básica }\end{array}$ & $\begin{array}{lr}\text { Contribuição de uma trilha } \\
\text { ecológica } & \text { para } \\
\text { sensibilização } & \text { ambiental } \\
\text { de estudantes } & \end{array}$ \\
\hline 6 & Comunidade & $\begin{array}{l}\text { Educadoras } \\
\text { ambientais } \\
\text { comunitárias }\end{array}$ & $\begin{array}{l}\text { Levantar temas trazidos } \\
\text { pelas educadoras que } \\
\text { dialogassem com o } \\
\text { movimento por justiça } \\
\text { ambiental e com as } \\
\text { discussões de gênero. }\end{array}$ \\
\hline 7 & Comunidade & Policiais militares & $\begin{array}{l}\text { Olhares de policiais } \\
\text { militares sobre crime } \\
\text { ambiental, fruto de projeto } \\
\text { de instituições privadas de } \\
\text { ensino }\end{array}$ \\
\hline 8 & $\begin{array}{l}\text { Comunidade/Exposição fruto } \\
\text { de um projeto de ONG }\end{array}$ & $\begin{array}{lr}\text { Estudantes } & \mathrm{e} \\
\text { visitantes } & \mathrm{da} \\
\text { exposição } & \text { (situada } \\
\text { em uma } & \text { escola } \\
\text { pública) } & \end{array}$ & $\begin{array}{l}\text { Potencialidade da } \\
\text { exposição } \\
\text { espaço de } \\
\text { ambiental }\end{array}$ \\
\hline 9 & $\mid \begin{array}{lll}\text { Centro de Apoio } & \text { e } \\
\text { Reintegração da Criança } & \text { e } \\
\text { Adolescente (CARCA) } & \end{array}$ & $\begin{array}{l}\text { Crianças } \\
\text { adolescentes } \\
\text { Centro }\end{array}$ & $\begin{array}{lcr}\text { Concepções } & \text { prévias } & \text { dos } \\
\text { estudantes } & \text { sobre } & \text { as } \\
\text { serpentes } & & \end{array}$ \\
\hline
\end{tabular}




\begin{tabular}{|l|l|l|l|}
\hline 10 & $\begin{array}{l}\text { Universidade, projeto de } \\
\text { extensão. }\end{array}$ & $\begin{array}{l}\text { Alunos participantes } \\
\text { de coletivo educador }\end{array}$ & $\begin{array}{l}\text { O papel dos coletivos } \\
\text { educadores na formação } \\
\text { de seus integrantes }\end{array}$ \\
\hline 11 & Segurança alimentar & $\begin{array}{l}\text { Tessíveis contribuições do } \\
\text { alima da segurança } \\
\text { processo de ensino e } \\
\text { aprendizagem com o tema } \\
\text { segurança alimentar na } \\
\text { compreensão crítica das } \\
\text { relações entre humanidade } \\
\text { naturezar e de } \\
\text { nesigualdade dentro da } \\
\text { sociedade. }\end{array}$ \\
\hline
\end{tabular}

Quadro 1 - Caracterização dos trabalhos/pesquisas apresentadas no GDP EA e Contexto Não Escolar no IX EPEA. Fonte: Elaborado pelos autores.

Pode-se observar que as pesquisas apresentadas em 2017 se concentraram no contexto das Unidades de Conservação (03) e das comunidades locais (03). Conforme apontado em Saisse et al. (2016), as áreas protegidas sempre se mostraram como um contexto relevante nesse GDP, especialmente como espaço para sensibilização ambiental de diversos públicos. $\mathrm{Na}$ leitura dos trabalhos apresentados em 2015, as autoras destacaram, também, as comunidades como um dos contextos pertencentes ao GDP, e elencaram, ainda, como contextos encontrados, as Organizações não governamentais (ONGs) e empresas, licenciamento ambiental e gestão ambiental pública, e a gestão de riscos ecológicos.

No IX EPEA, apenas um trabalho pesquisado esteve ligado à ONG, apesar de este não ser seu contexto, e nenhuma pesquisa analisou um processo educativo relacionado à empresa ou à gestão ambiental pública.

Além disso, alguns trabalhos podem gerar dúvidas quanto ao contexto no qual estariam melhor inseridos. Por exemplo, o trabalho 5 poderia se enquadrar no GDP EA $e$ contextos escolares, se considerarmos que a trilha foi toda idealizada e conduzida pelo grupo de uma escola pública (CEFET) para seus alunos, e, portanto, estaria voltado ao ensino formal, mesmo sendo um processo que aconteceu em um ambiente fora da escola. Apesar de o contexto da pesquisa ser em um espaço não formal, se enquadraria em um contexto escolar, se assim admitirmos a proposta discutida no item anterior. Porém, como já apontado, não há consenso quanto a esse ponto, e, por isso, há interpretações que considerariam essa pesquisa mais adequada no GDP EA e Contexto Não Escolar.

Uma situação inversa, mas com o mesmo pressuposto de reflexão, refere-se ao trabalho 8, sobre uma exposição enquanto espaço de sensibilização ambiental. Esta se encontrava fisicamente em uma escola, e poderia ser considerada como uma pesquisa em contexto escolar. Entretanto, outra interpretação poderia dizer que o ambiente formal era apenas o espaço/local físico, mas quem participou da pesquisa foram estudantes e visitantes, não estando relacionada a nenhuma prática escolar. A exposição foi resultado de um projeto de uma ONG, que se utilizou de um espaço escolar. Nesse caso, o espaço foi escolar, mas não envolveu a instituição e os procedimentos da escola.

O trabalho 9 investigou as concepções de estudantes de um centro que faz parte do aparato público, o Centro de Apoio e Reintegração da Criança e Adolescente (CARCA), porém seu objetivo em nada se relaciona com a política pública, sendo o centro apenas o espaço/contexto em que foi realizada a pesquisa pela autora ter proximidade com o mesmo tal informação somente foi compreendida a partir do relato da autora durante sua apresentação do GDP do EPEA. 
Uma questão que pode ser dúbia relaciona-se às pesquisas no contexto da Universidade. $\mathrm{O}$ trabalho 10 investigou a potencialidade do coletivo educador formado a partir de um projeto de extensão universitária como espaço formador de educadores. Esse coletivo realiza atividades e ações de educação ambiental na comunidade. A ação desse coletivo, e, portanto, seu potencial formador, se encontra fora do espaço formal da Universidade, porém, está relacionada a ela por ser um projeto de extensão. Seria, então, considerada enquanto uma pesquisa no contexto escolar ou não escolar?

Acreditamos que o trabalho 11 apresentou-se mais próximo do GDP Questões epistemológicas,observação reforçada pelas autoras no debate após a apresentação do trabalho. Estas ponderaram ter dúvidas se estariam no GDP mais adequado, se comparando inclusive aos outros trabalhos apresentados. De acordo com as autoras, o foco e objetivo de investigação de sua pesquisa são processos de ensino e aprendizagem voltados à segurança alimentar, que podem ser realizados em contextos quaisquer, mas que normalmente seriam mais propensos a ser realizados em contextos não escolares.

Já tendo observado a interação dos trabalhos do GDP EA e Contexto Não Escolar, tivemos o interesse em verificar, no sentido inverso, os trabalhos apresentados nos outros GDPs nessa mesma edição do evento, na intenção de analisar se algum outro trabalho poderia ter relação ou estar mais enquadrado ao contexto não escolar. Conforme ilustra o Quadro 2, foram observadas as pesquisas apresentadas nos demais GDPs do IX EPEA.

\begin{tabular}{|c|c|c|}
\hline \multirow[t]{2}{*}{ GDPs } & \multicolumn{2}{|c|}{$\begin{array}{l}\text { Trabalhos com relação com GDP EA e contextos não } \\
\text { escolares }\end{array}$} \\
\hline & $\begin{array}{l}\text { Quantida } \\
\text { de }\end{array}$ & Temas/objetos de pesquisa \\
\hline Políticas públicas & 3 & $\begin{array}{l}\text { - Considerações sobre potencial político pedagógico } \\
\text { de conselhos gestores de UC } \\
\text { - Análise de um projeto de EA (da Prefeitura) no } \\
\text { Morro da Formiga, RJ } \\
\text { - Levantamento do perfil laboral de marisqueiras, } \\
\text { fruto de uma oficina aplicada em uma comunidade, } \\
\text { parte de um projeto de condicionante de } \\
\text { licenciamento ambiental }\end{array}$ \\
\hline Contexto escolar & 2 & $\begin{array}{l}\text { - O desastre da Samarco: a cobertura de diferentes } \\
\text { mídias e sua importância para a educação ambiental } \\
\text { - Educação Ambiental e o Uso de Agrotóxicos: } \\
\text { possíveis relações entre a educação e o mundo do } \\
\text { trabalho }\end{array}$ \\
\hline Movimentos sociais & 1 & $\begin{array}{l}\text { Análise do Projeto Alfabetização Científica no } \\
\text { Contexto da Cidadania Socioambiental (ACCS), que } \\
\text { analisa a formação de educadores ambientais em } \\
\text { diálogo com espaços não formais de educação } \\
\text { (inspirado em ações de um Coletivo Educador). }\end{array}$ \\
\hline Culturas & 1 & $\begin{array}{l}\text { Apresentação de estratégia para contextualização de } \\
\text { propostas de Educação Ambiental às realidades de } \\
\text { comunidades do Vale do Jequitinhonha (EA de base } \\
\text { comunitária) }\end{array}$ \\
\hline
\end{tabular}




\begin{tabular}{|l|l|l|}
\hline Questões metodológicas & 1 & $\begin{array}{l}\text { Educação ambiental crítica e conflitos } \\
\text { socioambientais na área de abrangência do Programa } \\
\text { de Educação Ambiental com Comunidades Costeiras }\end{array}$ \\
\hline $\begin{array}{l}\text { Formação de } \\
\text { professores/educadores }\end{array}$ & 0 & \\
\hline Questões epistemológicas & 0 & \\
\hline
\end{tabular}

Quadro 2 - Trabalhos de outros GDPs com relação com o GDP EA e Contexto Não EscolarFonte: Elaborado pelos autores.

Do total, de acordo com o critério adotado, que será explicado a seguir para cada uma das pesquisas apontadas, apenas oito trabalhos apresentados em outros GDPs têm alguma relação com o contexto não escolar.

O GDP que apresentou a maior quantidade de trabalhos com alguma sobreposição foi o de Políticas Públicas (03). Trata-se de pesquisas que analisam processos educativos em espaços/contextos não escolares, mas que são resultados diretos de políticas públicas. Nesses casos, os autores pareceram buscar o principal objetivo da sua pesquisa para enquadrar no GDP. O primeiro caso, do potencial político pedagógico de conselhos gestores de UCs, apesar da Unidade de Conservação perfazer um contexto não escolar, a análise foi feita diretamente acerca da política pública, sendo um caso de clara sobreposição, assim como poderia acontecer em pesquisas sobre projetos ou ações de educação ambiental condicionantes do licenciamento ambiental, portanto, também fruto de uma política pública.

Também se encontra nesse debate o trabalho de levantamento do perfil laboral de marisqueiras, resultado de uma oficina aplicada em uma comunidade, portanto, considerado um contexto não escolar, mas parte de um projeto de condicionante de licenciamento, então, diretamente relacionada a uma política pública. Outro trabalho, ainda nesse GDP, enfoca um projeto de educação ambiental da Prefeitura, no Morro da Formiga, no Rio de Janeiro. Esse, apesar de ser resultado de uma política pública, poderia facilmente se enquadrar como contexto não escolar, visto que traz uma análise das práticas e objetivos de um projeto realizado diretamente na/com comunidade. Nesses casos, para ver em qual GDP seria melhor enquadrada a pesquisa, teria que se observar, com cuidado, o objetivo e objeto de análise, questionando se o foco se concentra na análise da política pública ou nos processos desencadeados dentro de ações advindas da política pública.

Em relação ao GDP EA e Contexto Escolar, um dos trabalhos é diretamente sobre o papel das mídias em relação a uma questão ambiental, no caso, um desastre ambiental. Apesar de os autores, em sua conclusão de pesquisa, trazerem o espaço escolar ao dizer que estudos sobre como as mídias cobrem desastres ambientais pode contribuir para os processos de educação ambiental nas escolas, o contexto da pesquisa são as mídias, mais adequado como contexto não escolar.

O segundo trabalho teve como objetivo a exploração de possíveis sentidos relacionados à educação e ao mundo do trabalho, a partir da análise das entrevistas realizadas com quatro agentes sociais envolvidos em atividades de educação ambiental, na tentativa de buscar responder até que ponto as práticas de educação ambiental são significadas pelos agentes sociais da comunidade como possíveis caminhos de formação política e de construção da cidadania. Assim, mesmo que algumas das práticas que esses agentes realizam sejam relacionadas à escola, o objeto de análise da pesquisa são os agentes sociais da comunidade, o que se relaciona com o contexto não escolar, tanto no seu objetivo quanto nos sujeitos pesquisados. 
O GDP EA de Movimentos Sociais tem uma relação intrínseca com o contexto não escolar, seja pelo espaço, objetivo ou sujeitos analisados, porém, os trabalhos apresentados nesse GDP eram bem específicos de processos realizados ou relacionados a movimentos sociais. A única exceção foi uma pesquisa que buscou analisar um projeto para formação de educadores ambientais em diálogo com espaços não formais de educação (inspirado em ações de um Coletivo Educador). Além do GDP EA e Contexto Não Escolar, essa pesquisa também tem relação com o GDP EA e Formação de Educadores-Professores.

Os GDPs EA e Culturas e EA e Questões metodológicas apresentaram uma pesquisa relacionada com o contexto não escolar. $\mathrm{O}$ primeiro teve como objeto de análise a educação ambiental de base comunitária, e pretendeu apresentar uma estratégia para a contextualização de propostas de EA às realidades de comunidades de uma região. Ainda que tenha sido considerada a cultura local enquanto ponto de partida metodológico, como os autores colocaram, pode-se discutir se realmente esse é o foco da pesquisa, ou se são os processos de ensino-aprendizagem em comunidades, o que, de fato, se enquadraria como um contexto não escolar. Ainda, por levantar propostas metodológicas, poderia ser enquadrado no GDP EA $e$ Questões metodológicas. Trazendo agora esse GDP, um dos trabalhos apresentados nele analisou os conflitos socioambientais vivenciados por comunidades pesqueiras da área de abrangência do Programa de Educação Ambiental com Comunidades Costeiras (PEAC), sendo um projeto condicionante do licenciamento. Esse caso retoma a discussão trazida quando da análise dos trabalhos do GDP EA e Políticas Públicas, ou seja, estaria enquadrado em contexto não escolar, em política pública ou nos dois?

Cabe ressaltar que não se pretende com isso estabelecer uma competição entre os GDPs mas, sim, contribuir para que essas correlações sejam vistas pelo conjunto de pesquisadores que participam desse importante espaço acadêmico de produção e socialização de conhecimento que é o EPEA, além de ampliar o entendimento das pesquisas que melhor se enquadrariam no GDP EA e Contexto Não Escolar.

Essas reflexões sobre o campo e sua temática específica intencionam, ainda, estimular os grupos de discussão para que dialoguem e ampliem as trocas e as interações entre suas pesquisas e análises, enquadradas e organizadas por afinidades nos GDPs, para fins organizativos, de modo a contribuir, assim, com o campo científico da educação ambiental. Observando e analisando a partir dos exemplos concretos, ou seja, dos trabalhos apresentados no GDP desse último EPEA, como realizado nesta presente pesquisa, tivemos a intenção de facilitar e contribuir no processo de reflexão e de tomada de decisão dos pesquisadores em relação aos seus respectivos GDPs de interesse.

\section{Considerações finais}

O campo da pesquisa em educação ambiental se expande a cada ano, estimulado pelos programas de pós-graduação e pela necessidade de melhor compreender as políticas e propostas educativas realizadas em busca de uma outra relação da sociedade com o ambiente. O EPEA tem papel fundamental, desde a sua criação, no intercâmbio entre os pesquisadores e no aprofundamento das questões desse campo.

O GDP em EA e Contexto Não Escolar tem acolhido investigações relevantes sobre o tema, proporcionado o conhecimento de diversos contextos onde as pesquisas são realizadas e, aos poucos, vem consolidando sua identidade e especificidade. A última edição do EPEA constata o aumento do número de trabalhos inscritos e aprovados para o GDP, refletindo amadurecimento nessa área de pesquisa. As pesquisas trazidas ao longo das quatro edições desse GDP vêm mostrando os desafios e potencialidades do mesmo, além de contribuir para um maior conhecimento do campo. 
Por outro lado, questões como os limites para o enquadramento quanto ao que denominamos como não escolar, nas pesquisas, ainda estão em processo de apuração. Investigar esses limites se constitui como uma direção possível para futuras investigações, que se concentrem, além dos espaços e sujeitos dos trabalhos realizados nesse contexto, nas metodologias e nos referenciais teóricos utilizados, a fim de caracterizar melhor o campo e dar material para outros desdobramentos de pesquisas.

Isso se torna relevante, pois o campo de pesquisa/contexto de pesquisa não escolar tem suas particularidades para além da simples distinção e separação entre formal e não formal, apesar das sobreposições que existem e dos questionamentos que ainda fazemos sobre sua delimitação e seus vínculos com outras temáticas/GDPs.

Seguem, então, essas questões e desafios, envolvendo pesquisadores de diversos campos de formação e de regiões do país, provocando novos estudos e estimulando novos estudantes. A continuidade das pesquisas que tratam desses assuntos apresenta bastante importância para o campo da pesquisa em Educação Ambiental, sendo este um campo múltiplo, sob aspectos teórico-metodológicos, com diferentes práticas pedagógicas, e como forma de resistência ao modelo de desenvolvimento econômico e superação da crise ambiental posta à sociedade/modernidade.

\section{Referências}

BRASIL. ProNEA - Programa Nacional de Educação Ambiental.Ministério do Meio Ambiente, Departamento de Educação Ambiental; Ministério da Educação, Coordenação Geral de Educação Ambiental. 3 ed. Brasília: MMA, 2005.

HIGUCHI, M.I.G.; MAROTI, P.S. Espacialidades e socialidades da educação ambiental além dos muros da escola. Pesquisa em Educação Ambiental, Rio Claro, v. 9, n. 1, p. 95-109, jan./jul., 2014. Disponível

em: <http://www.periodicos.rc.biblioteca.unesp.br/index.php/pesquisa/article/view/8855/6172>. Acesso em: 06 mar. 2018.

HIGUCHI, M.I.G.; ZATTONI, M.; BUENO, F.P. Educação ambiental em contextos não escolares: definindo, problematizando e exemplificando. Pesquisa em Educação Ambiental, Rio Claro, v. 7, n. 2, p. 119-131, jul./dez., 2012. Disponível em: <http://www.periodicos.rc.biblioteca.unesp.br/index.php/pesquisa/article/view/6865/4968>. Acesso em: 06 fev. 2013.

MARANDINO, M. Faz sentido ainda propor a separação entre os termos educação formal, não formal e informal? Ciência e Educação,Bauru, v. 23, n. 4, p. 811-816, out./dez., 2017. Disponível em: $<$ http://www.scielo.br/scielo.php?script=sci_arttext\&pid=S1516-73132017000400811 $\& \operatorname{lng}=\mathrm{pt} \& \mathrm{tlng}=\mathrm{pt}>$. Acesso em: 15 fev. 2018.

MATERAZI, J. Estruturas e espaços educadores. In: FERRARO JR., L.A. (Org.). Encontros $e$ caminhos: formação de educadoras(es) ambientais e coletivos educadores. Brasília: MMA, Diretoria de Educação Ambiental 2005, p. 159-173.

PALHARES, J.A. Os sítios de educação e socialização juvenis: experiências e representações num contexto não escolar. Educação, Sociedade \& Culturas, Porto, n. 27, p. 109-130. 2008. Disponível em: <https://www.fpce.up.pt/ciie/revistaesc/ESC27/27_jose.pdf>. Acesso em: 17 mar. 2018.

QUINTAS, J.S. Educação no processo de Gestão Ambiental: uma proposta de educação ambiental transformadora e emancipatória. In: LAYRARGUES, P. P. (Coord.). Identidades da educação ambiental brasileira. Brasília: MMA, 2004. p. 113-140. 
SAISSE, M.V.; OLIVEIRA, H.T. de; DORNFELD, C.B.; AMARAL, A.Q. Pesquisa em educação ambiental em contextos não escolares: pertinência do recorte e interfaces entre os grupos de discussão dos Encontros de Pesquisa em Educação Ambiental (EPEA's). Pesquisa em Educação Ambiental, Rio Claro, v. 11, n. 2, p. 134-145, jul./dez., 2016. Disponível em: <http://www.periodicos.rc.biblioteca.unesp.br/index.php/pesquisa/article/view/11973/7913>. Acesso em: 17 mar. 2018. 